\title{
Problem of Foreign Body in GI Tract
}

\author{
Yahya Daneshbod, ${ }^{1}$ Abdolrasoul Talei, ${ }^{2}$ Shahrzad Negahban, ${ }^{1}$ Hossein Soleimanpour, ${ }^{1}$ \\ Azita Aledavoud, ${ }^{1}$ Neda Bagheri, ${ }^{1}$ Mahsa Khanlari, ${ }^{1}$ and Khosrow Daneshbod ${ }^{1}$ \\ ${ }^{1}$ Department of Surgical Pathology, Dr Daneshled, Pathology Laboratory, Shiraz 71437, Iran \\ ${ }^{2}$ Department of Surgery, Faghihi Haspital, Shiraz 71345, Iran
}

Received 29 July 2011; Accepted 13 September 2011

Academic Editor: Raj K. Goyal

Most foreign bodies pass through the gastrointestinal tract uneventful. We report of a case of inadvertently ingested foreign body, which by endoscopy simulated a polyp and on biopsy reported as cancer, so the patient underwent an unnecessary major operation. This report emphasizes the importance of resemblance of foreign bodies with gastrointestinal neoplasm, and endoscopists, surgeons and pathologists should consider this entity in their daily practice.

KEYWORDS: GI tract, polyp, tumor, foreign body 


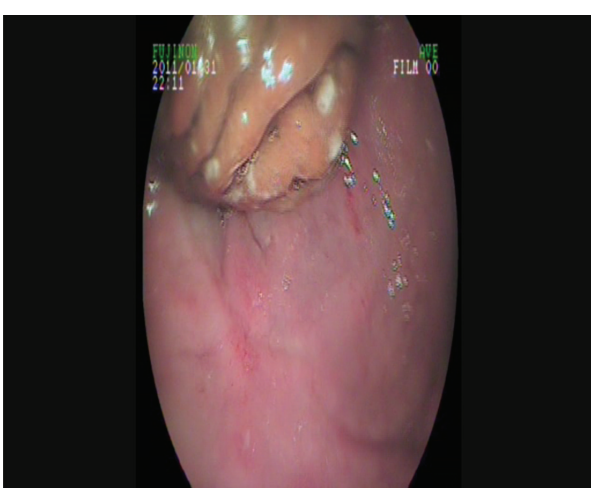

(a)

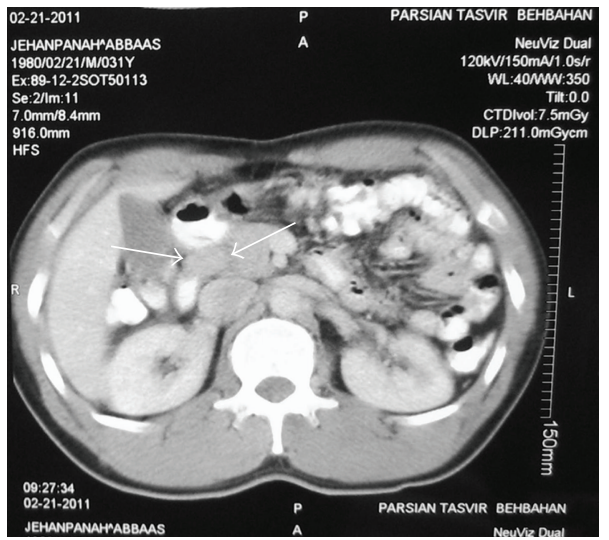

(c)

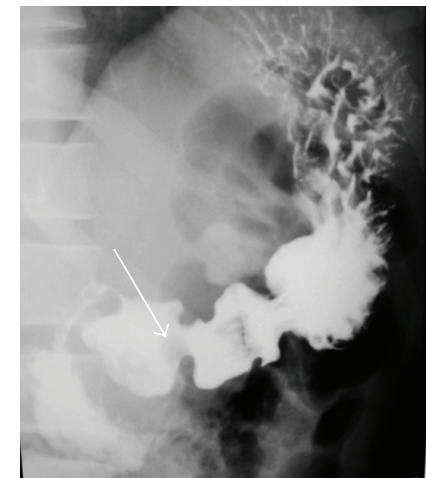

(b)

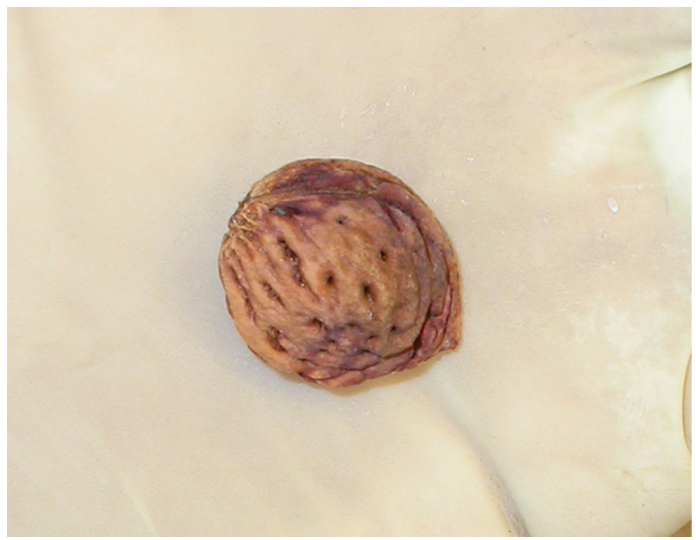

(d)

FIGURE 1: (a) Endoscopy showed $2 \mathrm{~cm}$ polypoid mass with rugal fold-like surface resembling stomach mucosal folds in proximal duodenum. (b) Upper GI series showed an oval lucent shadow (filling defect) in the duodenal bulb, close to the outlet of pylorus. (c) Abdominal CT scan with contrast showed entrapment of contrast in the stomach and duodenum at the level of second lumbar vertebra suggestive of a soft tissue mass or nonopaque particle. (d) Peach kernel found impacted in duodenum.

In March 2011, a 32-year-old man presented with on and off epigastric pain and vomiting three years ago. On physical examination he had a soft nontender abdomen and normal vital signs. With the impression of acid peptic disease he received $\mathrm{H} 2$ receptor antagonists, with partial improvement. A month later his symptoms recurred and endoscopy was performed. Endoscopy showed edematous pylorus, and entering the bulb there was a $2 \mathrm{~cm}$ polypoid mass with rugal fold-like surface resembling stomach mucosal folds and ulcerative lesions in proximal duodenum (Figure 1). Biopsy was made from duodenal lesions. Upper GI series showed an oval lucent shadow (filling defect) in the duodenal bulb, close to the outlet of pylorus (Figure 1(b), arrow) suggestive of Brunner's gland hyperplasia/adenoma. Abdominal CT scan with contrast showed entrapment of contrast in the stomach and duodenum at the level of second lumbar vertebra suggestive of a soft tissue mass or nonopaque particle (Figure 1(c), arrow). Biopsy of the bulb area was reported as adenocarcinoma. Whipple's operation was performed. Gross and microscopic pathology of the whole resected specimen was positive only for an ulcerative area in proximal bulb and interestingly an impacted peach kernel was found beside it (Figure 1(d)). Review of the previous pathology showed regenerative glands with no tumor. The past history of the patient was positive for eating a peach, with sudden swallowing after bending to buckle his shoes four years ago. No kernel passing occurred in his stool.

Ingestion of various types of foreign bodies has been reported. Most ingested foreign bodies pass through the gastrointestinal tract spontaneously without causing untoward effects. However, sometimes these foreign bodies cause obstruction, ulcerate, or perforation of the gastrointestinal tract [1]. 
Endoscopic removal should be performed by a skilled endoscopist. If this is not possible or unsuccessful, a surgical approach is recommended [2].

\section{REFERENCES}

[1] L. Carp, "Foreign body in the intestine," Annals of Surgery, vol. 85, pp. 575-951, 1927.

[2] M. H. Strain, D. M. Chisevescu, and S. Potopea, "Successful endoscopic treatment of an unusual cause of lower gastrointestinal bleeding using the OVESCO system," Journal of Gastrointestinal and Liver Diseases, vol. 20, no. 1, pp. 85-87, 2011.

\section{This article should be cited as follows:}

Yahya Daneshbod, Abdolrasoul Talei, Shahrzad Negahban, Hossein Soleimanpour, Azita Aledavoud, Neda Bagheri, Mahsa Khanlari, and Khosrow Daneshbod, "Problem of Foreign Body in GI Tract," TheScientificWorldJOURNAL, vol. 11, pp. 2147-2149, 2011. 


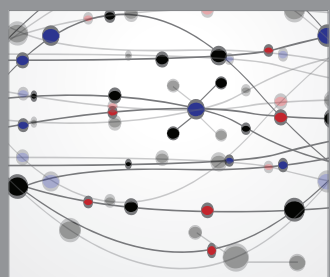

The Scientific World Journal
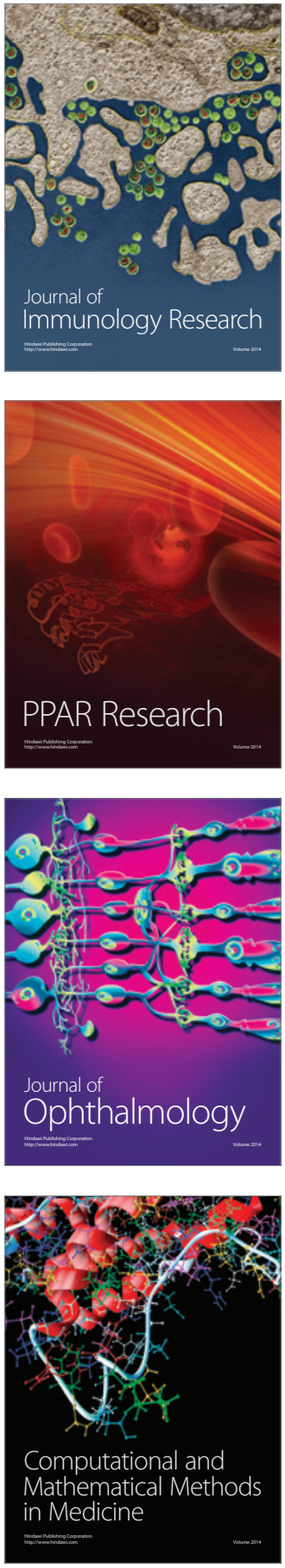

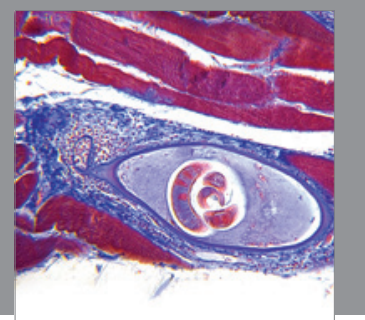

Gastroenterology

Research and Practice
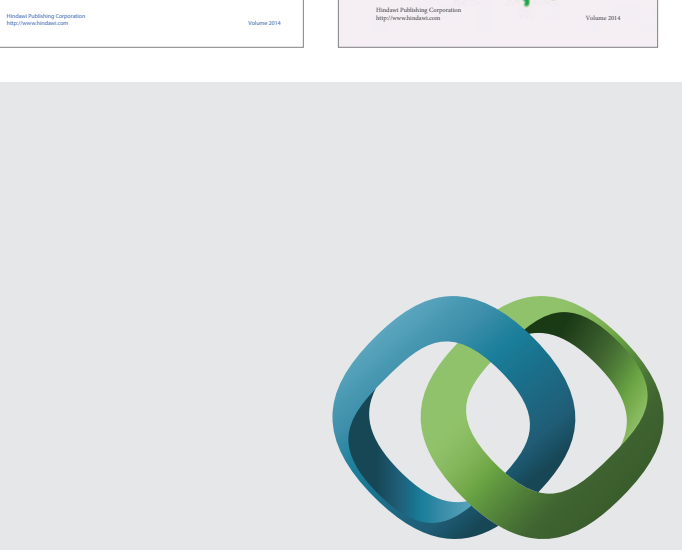

\section{Hindawi}

Submit your manuscripts at

http://www.hindawi.com
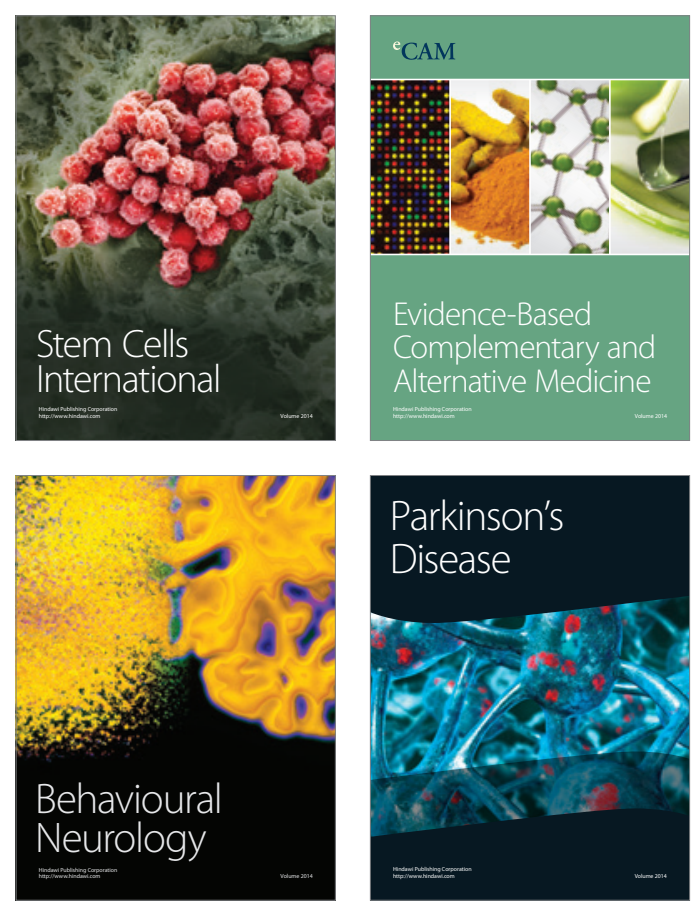

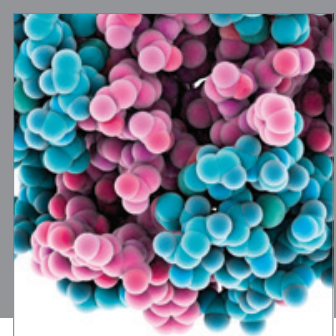

Journal of
Diabetes Research

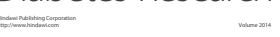

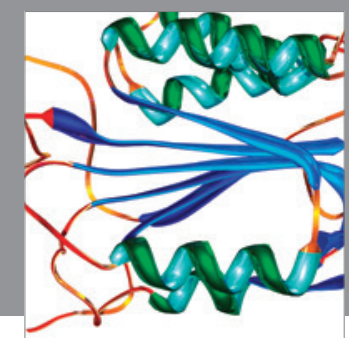

Disease Markers
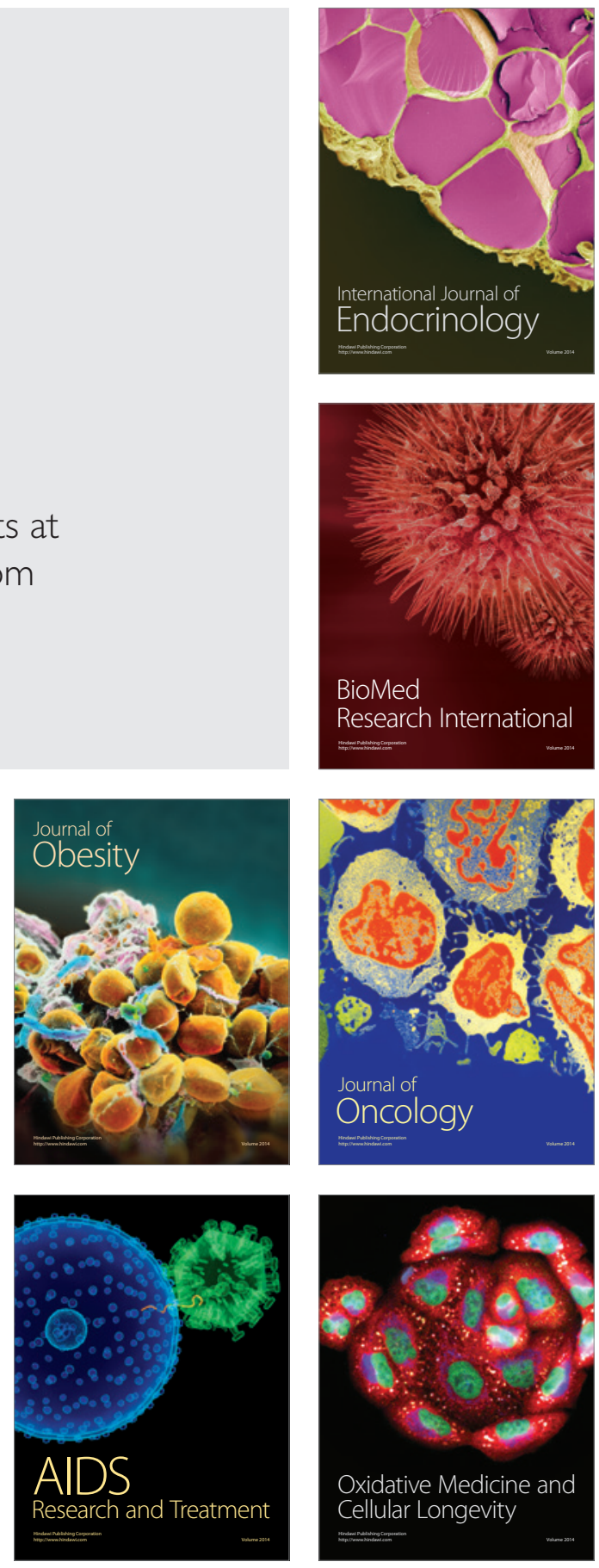